\title{
Study on Service-Oriented Manufacture in Dong-Feng Peugeot Citroen Automobile Company LIMITED
}

\author{
Yihong Xu \\ Jiang Han University Wu Han city circle manufacturing development study center \\ Wuhan, 430056, China \\ Xuyihong_wh@hotmail.com
}

\begin{abstract}
Service-oriented manufacturing is a new manufacture form which combines manufacture with service to cater to customers' diverse needs with the globalization of economy and the development of technology. This paper will make a case study of the service-oriented manufacturing in Dong-Feng Citroen Peugeot Company LIMITED and discuss how to adapt the general manufacture rules and some successful experience abroad to Chinese automobile manufacture enterprises, as well as offer some advice on how to transform. In this paper, literature research, comparative research and case study will be adopted. The features of DPCA's manufacture, the form of service-oriented enterprises, and the use of service-oriented manufacturing will be introduced, and advice on solving the problems arising from the manufacturing and full-service will be given.Researchers Researchers draw the condusion that DPCA's transformation of inner study, manufacture and marketing which is widely popularized and applied in many fields of the company, the internalization of service concept and enterprise culture into the extended section of the value chain, focusing on the customers' value, establishing the value system of service-oriented automobile enterprises. All these can be instructive and guiding in transforming the traditional automobile manufacturing enterprise into service-oriented enterprise.
\end{abstract}

Keywords-Service-oriented Manufacture; Automobile Manufacture; Full Value Chain; Transformation; Logistics

\section{INTRODUCTION}

Automobile manufacture is the pillar industry of national economy, which is an important carrier of supporting the transformation and upgrading as well as innovation-driven of the national economy, it shows a whole nation's strength of technology.

Though Chinese automobile manufacture started comparatively late, after 60 years' development, it has improved a lot, especially in recent years, and now it is integrating into the global automobile manufacture system. Being published by CINIC, Chinese Automobile Market deep Research And Investment Strategy Research From 2014-2019, after the 11th Five-year Plan, the production and marketing of Chinese automobile keeps growing fast, the output of automobile increased from 5,707,700 in 2005 to $22,116,800$ in 2013 , the sells increased from 5,758,200 in 2005 to $21,984,100$ in 2013 . The CAGR reaches $18.45 \%$ and $18.23 \%$. Till 2012, Chinese automobile output ranked the 1st in the world for 4 years stably; its position in the international automobile market has risen greatly, and it has become the most important automobile market in the world.

However, there is still a huge gap between Chinese automobile manufacture and the world leading automobile manufactures. NDRC (national development and reform commission)released The Notification of the suggestion in Automobile Industrial Structure in Dec. 25th 2006, it listed 5 problems in Chinese manufacturing enterprises: the signal of excess production capacity has appeared, and it may get worse, industrial organization structure is unreasonable, the advantages of business groups' captivity are not obvious, trans-regional and trans-department's merge and acquisitions are still hard to achieve, product structure restructuring is relatively backward, the upgrading of technology and product is slow, the proportion of sales of gas-guzzler is large, the sales of top technology and energy conservation products are comparatively bad, enterprise's capacity of developing is low, and they rely too much on importing technology and products. Part and finished automobile cannot reach synchronous development; manufacture is backward to the development of finished automobile. According to this, the manufacturing strategy and the form of manufacture must be reformed.

Service-oriented manufacturing is a new manufacture form combined with manufacture and service, develops in the background of economic globalization and diversity of customer's need and the rapid development of technology. The service-oriented manufacturing has been widely applied in construction, medical, furniture and other fields. However, how to apply the general rule and successful abroad experience into Chinese automobile manufacture enterprises still remains to be studied and solved.

DPCA is one of the earliest Chinese joint venture automobile companies, it has made a lot of explore and practice in promoting the production manufacturing into service-oriented manufacturing. The importance of service-oriented manufacturing for automobile enterprise, the value formation of the service-oriented enterprise and the service-oriented model's application and the accumulation of experience will be analyzed and studied. This paper has studied the feature of the manufacturing of DPCA and the methods and components transformation of automobile enterprises to give advice for the promotion of Chinese automobile enterprises into service-oriented enterprises. 


\section{THE ST ATEMENT ABOUT THIS SUBJECT BOTH AT HOME AND ABROAD}

\section{A. The development of the automobile manufacturing in the world}

In 2001, Tsinghua University published the book Manufacture in the 21st Century by Professor Paul
Kenneth Wright of the University of Californ ia. The book made a conclusion of the manufacturing form of U.S.A from 1970 s to the beginning of the 21 st century. The following forms of manufacturing has many classic models and cases which have a close connect with automobile manufacturing enterprise.

TABLE I. THE FEATURES AND DEVELOPMENT OF THE WORLDWIDE AUTOMOBILE MANUFACTURING

\begin{tabular}{|c|c|c|c|}
\hline year & The manufacturing form & Model enterprise & Feature \\
\hline 1910 & $\begin{array}{l}\text { Flow Line Production } \\
\text { Model }\end{array}$ & Ford Motor Company & Mass production, Taylor and Scientific Management Theory \\
\hline 1920 & $\begin{array}{c}\text { Multi-division Production } \\
\text { Model }\end{array}$ & General Motor Company & $\begin{array}{c}\text { Meet the requirements of customers, enhance enterprise } \\
\text { competitiveness }\end{array}$ \\
\hline 1970 & Team-made Model & Volvo Car Corporation & $\begin{array}{l}\text { Emphasize on the importance of subjective dynamics, corporate } \\
\text { responsibility and team spirit to enhance efficiency. }\end{array}$ \\
\hline 1980 & $\begin{array}{l}\text { Lean Manufacturing } \\
\text { Model }\end{array}$ & Toyota Motor & $\begin{array}{c}\text { Emphasize on eliminating the waste of excess inventory, use less labor } \\
\text { power, less space, less investment and less time to meet the } \\
\text { requirements of customers }\end{array}$ \\
\hline 1987 & $\begin{array}{l}\text { Mass Customization } \\
\text { Model }\end{array}$ & $\overline{\text { BMW }}$ & $\begin{array}{l}\text { Combine the traditional mass production and cust omization, emphasize } \\
\text { on meet the personal and diverse requirements of cust omers swiftly and } \\
\text { flexibly }\end{array}$ \\
\hline 1990 & $\begin{array}{l}\text { Virtual Manufacturing } \\
\text { Model }\end{array}$ & Volkswagenwerk & $\begin{array}{l}\text { Based on the market trend of diversity and individualization, the } \\
\text { manufacturing process should be as flexible and quick-respond to have } \\
\text { great competitiveness in the unpredictable and competitive market }\end{array}$ \\
\hline 1991 & $\begin{array}{l}\text { Agile Manufacturing } \\
\text { Model }\end{array}$ & General Motor Company & $\begin{array}{l}\text { The model adapts computer simulation and virtual reality technology, } \\
\text { uses group corporation to realize production design, process planning, } \\
\text { processing and manufacturing, performance analysis, quality } \\
\text { inspection, and each class's essential process of the enterprise's } \\
\text { management and controlto enhance the ability of each class's deciding } \\
\text { and control in the process of manufacturing }\end{array}$ \\
\hline 2000 & $\begin{array}{l}\text { Global Manufacturing } \\
\text { Model }\end{array}$ & $\begin{array}{c}\text { Renowned global } \\
\text { automobile manufacturing } \\
\text { enterprises }\end{array}$ & $\begin{array}{l}\text { The global manufacturing enterprises use global resources to explore } \\
\text { the global market, efficiency and acquire additional strategic value. }\end{array}$ \\
\hline
\end{tabular}

In 2008, Yi Jiaxu announced the 'Branding, PIGGGB' in his paper. This model is based on the production life cycle theory, set the automobile production life cycle theory as its main line, supported by informatization, globalization, greenization and branding, and sets the progress aim: time, quality, cost, service, resource and environment, pointing at economic benefit and sustainable development, having the features of multi manufacturing model integration, time-space dimension expansion, manufacturing objective multis ession.

\section{B. The status of the study of service-oriented manufacturing}

Service-oriented manufacturing is a brand new manufacturing model, emerged in the background of the combination of the manufacture and service industry, infiltrates towards the manufacture industry and service industry with the help of the networked corporation, providing the customers with product-service system, the enterprise will get profits by creating the customers the greatest value.

The developed industry countries have made a lot of studies of the service-oriented manufacturing, and the researchers are experts in the background, contents and methods of the study, and achieved a lot. The U.S.A named it Serviced Based Manufacturing; Australia named it Service-Enhanced Manufacturing, Japan named it service-oriented manufacturing, and The U.K named it Product Service System.

The domestic study of Service -oriented manufacturing began comparatively late — in 2003 , after 2005 , due to the need of the promotion of "made in China" the socialization of manufacturing industry began to attract the public attention, and become a hot project in the manufacturing study field. In 2007, Professor Sun Linyan published Service-oriented Manufacturing -the Advanced Manufacturing Mode in the 21st Century, which first put forward the concept of the service-oriented manufacturing, the influential study includes the study of the definition of the service-oriented manufacturing, origin of the value, and the main scientific issues by Sun Linyan, Zhao Xiao lei and Lin WenJin. The research of the product features and study basis of the product service value-added published by Ye Qin, Zheng Jichang, and Liu Ping. The discussion of the product servicing which is published by $\mathrm{Wu}$ Guosheng, Cheng Dazhong and Song Gaoge. The analys is of the enhancement of the manufacturing service' origin, status and development, and inner mechanism published by Lin Lei and Wu Guisheng.

In 2010, He Zhe and Sun Linyan believed that, in the view of the form of the concept, the service-oriented manufacturing went through a long period of time. It may date from the prediction the futurist made in the 1970s, after that, it mainly went through 4 stages. 
TABLE II.

THE STAGES WHICH CONCEPT OF SERVICE-ORIENTED MANUFACTURING WENT THROUGH

\begin{tabular}{|c|c|c|c|c|}
\hline Stage & Stage I & Stage II & Stage III & Stage IV \\
\hline Time & $1970 \mathrm{~s}$ & $1990 \mathrm{~s}$ & $2000-2005$ & After 2006 \\
\hline Symbol & $\begin{array}{l}\text { The put submit of the } \\
\text { service-oriented } \\
\text { manufacturing }\end{array}$ & $\begin{array}{l}\text { The manufacturing facing } \\
\text { service }\end{array}$ & Producer services & $\begin{array}{l}\text { Service-oriented } \\
\text { manufacturing }\end{array}$ \\
\hline $\begin{array}{l}\text { Industry } \\
\text { activity }\end{array}$ & $\begin{array}{l}\text { The developed countries } \\
\text { entered the age of service } \\
\text { economy }\end{array}$ & $\begin{array}{l}\text { The promotion of } \\
\text { international traditional } \\
\text { manufact uring enterprises } \\
\text { to service-oriented }\end{array}$ & $\begin{array}{l}\text { The promotion of } \\
\text { international top class } \\
\text { manufacturing enterprises } \\
\text { has completed }\end{array}$ & $\begin{array}{l}\text { Chinese enterprises began } \\
\text { the promotion of the } \\
\text { service-oriented } \\
\text { manufact uring and gave } \\
\text { new meanings to it }\end{array}$ \\
\hline
\end{tabular}

The overseas study of the service-oriented network is usually carried out with the theory of the product service. The relevant research of the Product Service System began in Netherlands and Scandinavian countries in the end of the 1990s. It mainly focuses on the introduction of the macro policy and concept level, far away from the deep question in this filed, lacks systematic research.

The establishment of the service-oriented is the integration of the supply chain and the combination of the manufacturing and service industry to some extent. Lawrence and Lorsch definite the integration as, "A state of corporation, which exists in the department and the department will endeavor under the requirement of environment." Lee pointed out 4 ways of the integration of the supply chain: the integration of information, corporation, share of resources, membership chain, share of venture and the definite plan of profit. Lee and Wang divide the supply chain according to the coordination degree between the integration members: integration of information, Synchronization schedule, work procedure and new business model.

The domestic research of service-oriented manufacturing network began with the research of the model of the service-oriented manufacturing, most of which are still in the stage of the introduction of the concept mode, which lacks the objective research of the specific field, let alone the micro aspect of the working procedure of the service-oriented network. What's more, the domestic research of this filed is only limited to several academic institutions, it didn't attract enough attention of the academic and enterprises. The example research connected to it is that in 2011, Liu Bingchun published the research about service-oriented manufacturing coordination mechanism in his dissertation. He believed the service-oriented manufacturing network was the model which could realize the management and organization of service-oriented manufacturing, whose core was establishing the system based on product which could lead the customers anticipate the whole procedure of the product service and service product and other activities to enhance the traditional value chain, thus could realize the expansion of the scale of the enterprise value chain. Meanwhile, with the corporation and division of labor of the node in the network, the integration of resource and innovation of knowledge, the competiveness of the manufacturing industry will be promoted. The establishment of the service-oriented network is of great significant of the promotion of the domestic economic development, the promotion of manufacturing industry and the enhancement of the enterprises' competitiveness.

In Oct. 2006, Chen Siyun put forward a few methods in the strategic extent of coordinating the supply chain of automobile in The Application of Supply Chain in the Automobile Manufacturing, they are: external coordination, coordination of back-end purchasing and coordination of the design procedure. In 2010, Sun Qinghua applied the theory of value net into the coordination management of the automobile supply chain, and the study and research were based on the strategy of the value net's automobile supply chain.

Some achievements could be seen on the research about the service-oriented manufacturing both domestic and overseas, however, it mainly focuses on the establishment of the concept model, the analysis of the value mechanism, the technology and the design, etc, it lacks the research based on the automobile industry.

III. THE FORMATION AND THE APPLICATION OF THE SERVICE-ORIENTED MANUFACTURE THEORY OF DPCA

\section{A. The Formation}

Aiming at the realization of the customer's value and concentrating on the customer's service is the key point of the "service-oriented manufacturing Theory". The "customer" here, the author mean, is not the terminal consumers, but the whole chain of customers. The variety of the customers' demand and the homogenization of the products make the company integrate the products and service, and come up with the solutions in all-wave. In the chain, the upstream should take the action of the downstream into consideration, hence the company must systemize the resources both integrally and externally. Furthermore, the service can fulfill the sensible value and the satisfaction of the customers, thus forming the value theory comforting the self-manufacture advantages.

Researchers can find that in the manufacturing part, that staffs in different factories and teams are customers in different identities. They serve, rely on and connect with each other. As the customers putting their eyes on services in chronological products, the company will change its emphases from quality and cost to the realization of the customers, the so-called "Products Living Period" and "Customer Regulating Procedure". In the heart of every employee in the company, the product as well as its enriching service and widening service can become the ways of realizing the customers' value. In the chain of the realization, the down streams will never be an accepter passively, but take part in the whole period. Maximally can the products from the upstream comfort the downstream in realizing the value of the company itself.

\section{B. The Application}

It is more and more obvious that the value chain is moving to services. Services has become a part of the 
essential competitiveness, in which the Service-Oriented Value Theory has been applied and worked. The departments have started various kinds of innovation. Not only had the upstream taken the downstream into consideration, but the downstream take part in the procedure of the manufacturing and transmitting spontaneously and actively as well. Customers and companies have become a whole part and have a great deal of intercourse, thus getting every part of the manufacture together to make progress and innovation, and the common value of customers and companies. At the same time, it reaches a win-win stage in all sides, and starts the formation of building up the common interest. Initiatively regulating and improving the service system make the company taking more advantages in competition. What's more, it makes the company earn more and gain more in the competitive environment.

What the author wants to emphasize is that, serviceoriented manufacturing is the composition of scientific and professional service, not the flock of those low-sided service. The innovative mode of DPCA stresses: 1. perfecting the service by innovation, making space for further interest to come up with targeted service. 2. Realizing the cooperatively compulsive service by getting customers in the procedure of manufacture and service. Centering in the customers, providing the whole "ProductService Packages" to customers. Then the Company will cling to the creed of "Making the best product, providing the best service", thus being the company everlas ting.

\section{THE TRAIT OF THE SERVICE-ORIENTED MANUFACT URE OF DPCA}

The Service-Oriented Manufacturing emphasizes making the conventional manufacture as essence, aiming to provide the product with service and the transition of basing on the product itself. Then the company will provide the honorific solutions. What's more, the company can bring about a new value and establish exclusive advantages. For automobile industry, the transformation of the service mode is paramount. In fact, the procedure itself is the transformation of the company from product provider to service provider. Firstly, the service-oriented manufacturing updates the efficiency through improving the use of the resources. Secondly, the company broadens the space for the increase of the value. Thirdly, the service attaching to the product produces increment for the company itself, which realizes the sustainable development of increasing the environmental friendliness and improves the company's "Green Value". Last but not the least, the extension of the service will guarantee the company making itself valuable.

\section{A. The Application of the Advantageous Resources of Service-Oriented Manufacture Value Chain}

According to the advantageous resources the incessant competitive advantages come from the integration and the utilization of the resources. In the service-oriented manufacturing, the company realizes the coordination manufacture by modularization producing and programmed improvement in the segment of manufacturing of automobiles thus enhances the efficiency and the quality. The help of the related industry forms the scale of economy. It improves the flexibility of manufacturing, and reduces the cost while manufacturing and trading, making more profits for the company. For instance, while providing components of the automobiles, different levels of suppliers (second and third level included) make more money. In the service segment, the company can formalize the economy scale by providing the "Product-Service pack" When the marg inal cost like wasted resources lessened, the company can basically realize making other profits in low cost. The elements of service, such as innovative abilities, designing tactics and researching experiences, make higher value for the company when put into the whole-scaled manufacturing application.

\section{B. The Creation of the "Green Value"}

DPCA is on the target of creating "Green Value", building ecological platform, developing the environmentfriendly company. Since 2000 , people pay more attention more on the pollution-free and environment-friendly products while consuming, for the deterioration of the living condition and the waste of the resources. Consequently, in the service system of the ServiceOriented Manufacturing, the company not only provides the service targeting to effectiveness, but not also observes professional service to improve the efficiency, reducing the waste while producing and using, lessening the expenditure both from the root and the branches. In DPCA, customers in different segments can partly join in the designing, producing and recycling. The company promotes the research and manufacture focusing on fulfilling the need from the customers, organically binding the product and the service together. Furthermore it can pave the ways for saving resources and reducing emissions. In this way, not only should the company shoulder the social responsibility itself, taking charge of recycling products, but stimulate the clean manufacture procedure and realize the green value by interiorizing exterior cost, extending the participant level in the product's living period. 


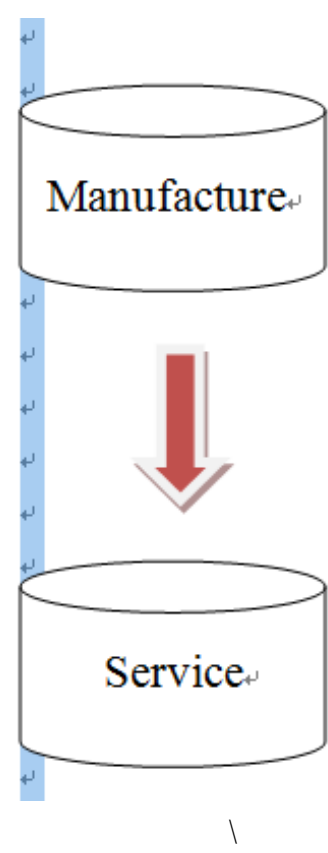

Figure 1. The Application of the Advantageous Resources of Service-Oriented Manufacture Value Chain
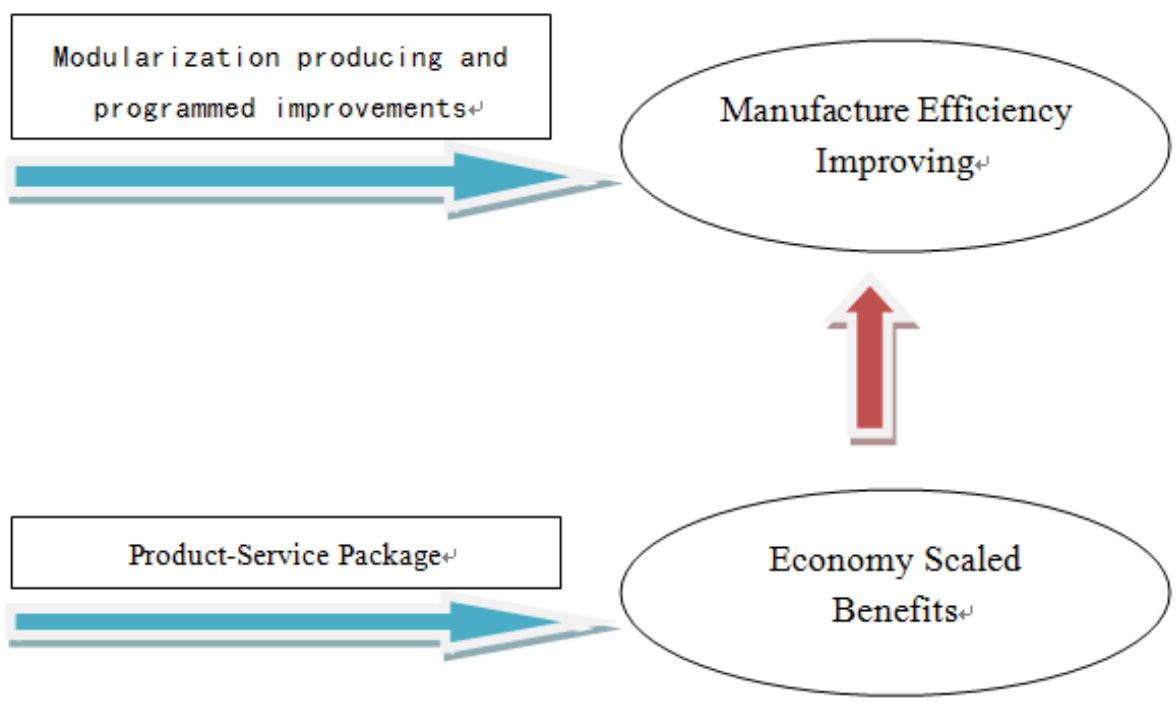

\section{The Application of Scaled-Customization and Sensorial Value}

The Service-Oriented Manufacturing maxi mazes its profit while realizing customer's value by product and service. In the Service-Oriented Manufacturing, the company attaches importance to manufacture, maximally fulfill the customized need by compounding the advantages both from large-scaled and customized manufacture without sacrificing benefits. Simultaneously, it can cater for the sensorial need from customers through observing the sensorial value. While basing on the balance of the sens orial "get" and "lose" in the process of acquiring product and service, the enterprise will reach the stage of pleasure from service and progress of sensible value.

\section{THE MAIN STRATEGY AND EFFECT OF THE DPCA'S SERVICE-ORIENTED MANUFACT URING TRANSITION}

\section{A. From producing products to full-service integrated solutions}

In the past, traditional productive manufacturing companies regard making products as their center. So they just focus on the products. However, service-oriented manufacturing companies have changed from focusing on the products to focusing on the product's life cycle and full-service integrated solutions. Aiming at meeting the needs of the clients. Set the clients' needs as the overall process of the operation. This changing of service model is really important especially in automobile manufacturing. In DPCA, at the beginning of research and design of the automobile products, they have built an overall process service system for the upstream and downstream clients based on the UEC design center. Attracting all the interesting parties (including technology partners, quality control party, information service party) to join in the service of the solution, to build a service designing system to supply a comprehensive integrated solution to the downstream clients. In this process, the downstream extend to the internal organization from the service interface of the manufacturing companies. For example, they participate in optimizing the design of products and the produce process, they offer some constructive suggestions and advice. In another way, the company stretches deep into the clients to notice and finds out their personality needs, and then collects them and gives back important information. Finally they form a totally new cooperation relationship.

\section{B. The changing from focusing on producing products to Post-Market service}

Recently, the changing from traditional products' manufacturing to service-oriented manufacturing in automobile manufacturing companies has a systematic and revolutionary impact on the research of the company and designing new products, optimizing the producing process, opening up and manages the market also creating the value inside the company. The DPCA is on the way to be a service-oriented manufacturing company. It's changing from only producing items, sailing and simply after-sales repair in the former time to integrated solutions, in other words that is to improve the value of the products by the customer service after sale. It accomplishes the progress of the products value and the brand value.

Post-Market refers to the summation of the service needs brought by customer service after the products delivery. In the formation of traditional manufacturing company, the inside service only stopped in the way of service among departments. The outside service is the limited after-sales service. Although the company can get some inspiration from the Post-Market, they seldom participate in the activities. Because of the lack of participation into the Post-Market, the automobile products' functions under the competitive circumstance and the role they played have been limited. To solve this problem, the company put forward an essential transformation of focusing on the Post-Market from the strategic level, transfer from offering basic before-sale and 
after-sale service to providing product's life cycle's service, stretching from value-added service to after-sales service.

\section{Build up a service concept of customer oriented}

The service-oriented manufacturing's core is customer oriented. The company must need to fully observe the real needs of the clients, stand on the clients' feet to think about the question and build the company's service concept that transfers from what researchers can provide to the clients to what do the customers need. The DPCA is carrying out the service concept of orienting all levels' clients, including the inside and outside clients, which makes it an accomplishment of transferring the service.

\section{Set up a service-oriented enterprise culture}

Enterprise culture is the marrow of an enterprise also the source and dynamism for a company's continuous development. The DPCA's principle line is to set up a service-oriented enterprise culture. And also other principle, such as, long term running, keep moving, right process lead to good results, employees and company grow up together and so on. Making the service-oriented enterprise culture system as its core to boost the company's development.

\section{E. The proficiency analysis of the DPCA's service- oriented manufacturing transformation}

The DPCA is one of the earliest auto joint ventures. From 1992 till now, it has been built for 20 years. However, in the first decade to 2002, the DPCA's main motorcycle type is Citroën Fukang hatchback. The company lack of motorcycle type, so that its products cannot compete well with others especially the hatchback had not been accepted by customers by that time. Its main manufacturing model is producing products and the fabricating cost is high, the additional value is low. So the company is always in deficit condition. In 2003, with the joining of Peugeot and the parent company of the DPCA, Dongfeng automobile company increased their investment; a new round of improvement has come. The company was in great need of a creative transformation to change its condition of deficit and improve its competitiveness. Under this advantageous background, the DPCA started carrying out the transformation to be a service-oriented manufacturing step by step. Taking the lean management system as its frame, the service-oriented manufacturing helped the company transfer from the pure producing company to a comprehensive service enterprise, also gave the efficiency support to its continuous development.

By the transition of the service-oriented manufacturing model and the applying of the service's concept, tools, ways, all the employees have deeply understood the meaning of the service-oriented manufacturing model. They also actively participated in the daily work's improvements. At the same time, it has been carried out in the full value chain, such as, the manufacturing providers, the dealers and so on to build a self-perfection and a keeping service system. In the recent 5 years, the DPCA's service-oriented manufacturing transition has been published to producing field, business field and many other areas to stretch the full value chain. Statistics suggested that the company's internal products department's UEC management has promoted all the researching areas to get three-stars grade in 2004.In the sales department, 20 dealers that have transferred into service-oriented model have increased $86.4 \%$ in its average quantity of sales in 3 months and the sales satisfaction index has increased by $19.5 \%$ in average. In the providing chain, 13 manufacturing providers that have taken service-oriented transition have improved by $67.4 \%$ in its 0 mile's PPM and $48 \%$ in its after-sale PPM, $10.8 \%$ in its quality of logistics. More than 7 hundred thous and finished automobiles have been sold and that was the best sale performance. In the research report of Chinese automobile after-sale service's satisfaction index published by the international authority market consulting institution. The DPCA's two brands both have come into the top 3. All fields' BSC indexes have accomplished a goal to challenge the top 2 .

TABLE III.

PRACTICE STATISTICS OF THE DPCA’S ALL FIELDS

\begin{tabular}{|c|c|c|c|c|}
\hline & UEC quantities & PP growth rate & $\begin{array}{c}\text { After-sales satisfactory index's growth } \\
\text { rate }\end{array}$ & Sale's growth rate \\
\hline 2010 & 2 & $21 \%$ & $3.2 \%$ & 37 \\
\hline 2011 & 9 & $25 \%$ & $4.7 \%$ & 42 \\
\hline 2012 & 16 & $32 \%$ & $11.3 \%$ & 45 \\
\hline 2013 & 23 & $43 \%$ & $15.4 \%$ & 55 \\
\hline 2014 & 37 & $48 \%$ & $19.5 \%$ & 70 \\
\hline
\end{tabular}

\section{CONCLUSIONS}

The automobile manufacturing company transfers from produce-oriented to service-oriented, builds a customerfocused service principle and stretch towards the full value chain. All of these are the company's strategic choices. The DPCA's transition of service idea, such as, the company's internal research and development, manufacturing, marketing and so on have been published and used in the enterprise's all fields. The service idea and the enterprise culture are absorbed to the value chain's developing side and it is made the core as creating the clients' value. DPCA has built up a service-oriented manufacturing's value system. All of above have the well function of reference or guidance for the traditional automobile manufacturing to transform into serviceoriented manufacturing enterprise.

\section{REFERENCES}

[1] General Office of the State Council's industry transition development plans (2011 2015)

[2] Neely A. Exploring the financial consequences of the sterilization of manufacturing [J]. Operations Management Research, 2008, 1(2):103-118.

[3] Hobo M, Watanabe C, Chen C J. Double spiral traject ory between retail, manufacturing and customers leads a way to serviceoriented manufacturing [J]. Technovation, 2006, 26(7):873-890. 
[4] Jag tap S, Johnson A. Requirements and use of in-service information in an engineering redesign task: case studies from the aerospace industry $[\mathrm{J}]$. Journal of the American Society for Information Science and Technology, 2010, 61(21):24442-2460.

[5] Engin A B. Comparative analysis for periodical and random servicing systems considering different working circumstances: a textile application [J]. Journal of manufacturing Systems, 2009, 28(4):89-97.

[6] Paul Kenneth Wright. $21^{\text {st }}$ century manufacturing [M].Beijing: Tsinghua University Press, 2002.

[7] Sun Linyan, service-oriented manufacturing: theory and practice [M].Beijing Tsinghua University Press, 2009:45-49, 134-138.

[8] Lin Lei, Wu Guisheng.The study on manufacturing's service improvements: origin, current situation and development [J] .scientific research management, 2006(1):91-99

[9] Sun Linyan, Wang Jian. Advanced manufact uring model---theory and practice [M]. Xi'an: Xi' an Jiaotong University Press, 2002:155-157

[10] Li Gang, Sun Linyan, Origin, Conception and Value Creation of Service-Embedded Manufacturing.[J]. Scientific development and countermeasure, 2009, 26(13):68-72.

[11] Chen Yangang, Liu Qinghua. The DPCA's lean management system's construction and practice. The DPCA.2013,(04)

[12] Liu Binchun, The service-oriented manufacturing's networks and running drills research [D]. Tianjin: Tianjin University's Doctor's degree easy, 2011.

[13] Wang Yanni.The research on auto core enterprise's innovation mechanism of network's effects on innovation performance.

[14] Sun Qinghua. The research based on the value net's automobile providing management.[D] Beijing: Beijing Jiaotong University,2010.

[15] Fang Hongwei. The example analysis of the transition of the automobile manufacturing company to the service-oriented enterprise. [J]. Chang An University's school journal.2013, (9):131-136

[16] Zhu Yongyue, Ma Zhiqiang and so on. A Review of Domestic and International Manufacturing Servitization: Based on Bibliometric Analysis.

[17] Yin Jiaxu.The study and its apply of the automobile manufacturing's producing model that based on the products' life cycle.[D].Chongqing University.

[18] Yan Binxiang. The research of Chinese automobile enterprise's cluster theory and its prove.[D].Beijing: Shanghai Jiaotong University,2008

[19] Huang Huiqun. Chinese national condition as the powerful industrial country and the industrial strategy to strengthen our country. $[\mathrm{J}]$.

[20] Wang Xiaoyin.The new progress of the research about the relationship between foreigner service enterprise and manufacturing in 21 st century.[J]Academy research.

[21] He Zhe, Sun Linyan, Debate of service or manufacturing and emergence of service-manufacturing based western historic experience.[J].Management journal,2012,(10):1515-1523. 